\title{
Identity, Connectedness, and Sexual Health in the Gay Sauna
}

\author{
Rusi Jaspal $^{1}\left(\mathbb{D} \cdot\right.$ Periklis Papaloukas $^{2}$
}

Published online: 24 February 2020

(C) The Author(s) 2020

\begin{abstract}
Introduction This study focuses on the meanings and experiences that men living in Leicester, UK attribute to the gay sauna, the role of the gay sauna in their sense of identity, and how they construe their sexual behavior in this context.

Methods In 2015, twenty male sauna users participated in a qualitative interview study. Data were analyzed using thematic analysis. Results The analysis yielded four themes: (1) identity authenticity in the gay sauna; (2) social connectedness among sauna users; (3) sexual risk and sexual health in the sauna; and (4) protecting the identity functions of the gay sauna. The themes show that engagement with the gay sauna can enhance feelings of identity authenticity and belongingness, and that individuals seek to protect these identity functions of the gay sauna despite recognizing the gay sauna as a "high-risk" environment. To protect identity, the notion of sexual risk is distanced from their own identities.

Discussion Sauna users may experience better psychological health as a result of frequenting the sauna - it may promote identity authenticity and belongingness, and alleviate isolation, loneliness, and depression. The promotion of sexual health information and services in gay saunas may enable us to access individuals who might not ordinarily engage with sexual health services.

Social Policy Implications There must be closer collaboration between sexual health services, sexual health outreach, and gay saunas in the area of sexual health, and identity concerns must be incorporated into the design of interventions.
\end{abstract}

Keywords Identity · Authenticity · Belongingness · Sexual health · Gay · Gay sauna

\section{Introduction}

Gay saunas (also referred to as gay bathhouses and steamhouses) are a commercial space in which gay, bisexual, and other men who have sex with men (MSM) ${ }^{1}$ can meet for sexual encounters. In the gay sauna, men can have relatively anonymous sexual encounters, sometimes with no verbal communication with their partners in either group or individual settings. There are records of gay men using saunas for sex in the fifteenth century but it was in the second half of the twentieth century that gay saunas became more widespread in London, New York, and other major cities (Bérubé, 1996).

\footnotetext{
${ }^{1}$ The term "gay sauna" is a recognized term but it is acknowledged that not all users of gay saunas necessarily self-identity as gay. A wide range of labels and categories are used to describe sexual identity among same-sex attracted men, including "gay," "bisexual," and "straight curious." In this article, the category "gay" is used to refer to all same-sex attracted men unless a more specific label or category has been used by a participant to describe himself.
}

Rusi Jaspal

rusi.jaspal@cantab.net

1 Nottingham Trent University, 50 Shakespeare Street, Nottingham NG1 4FQ, UK

2 De Montfort University, Leicester LE1 9BH, UK
The sexual health of sauna users has been a significant focus of both researchers and commentators (e.g., Debattista, 2015; Pollack, Woods, Blair, \& Binson, 2014). In Western, industrialized societies, gay men are at disproportionately high risk of HIV and other sexually transmitted infections (STIs) (Jaspal, 2018a). In the early stages of the HIV epidemic, gay saunas were identified as a key site of HIV transmission, and many were closed down. The HIV epidemic served to reinforce the stigma already appended to the gay sauna given its association with disease. Yet, gay saunas have now become an important context for raising awareness of safer sex and of enhancing HIV prevention efforts.

There has been limited research into the identities, experiences, and perceptions of gay sauna users (e.g., Keogh \& Weatherburn, 2000; Prior, 2009). Research in this area could facilitate the design of more effective HIV prevention and sexual health promotion interventions. Moreover, there has been no research into gay saunas specifically in small- and medium-sized cities in the UK, which omits significant populations of gay men at risk of HIV and other STIs. In order to address this lacuna in research, this article focuses on the meanings and experiences that gay men living in the English city of Leicester attribute to the gay sauna, the role of the sauna in their sense of identity, and how they construe their sexual behavior in this context. 


\section{Sexual Health Among Gay Men}

Of the 89,400 people living with HIV in the England in 2016, $51 \%$ were gay men (PHE, 2018a), and, of the 4370 new HIV diagnoses in 2017, 53\% $(n=2330)$ were among gay men (Nash et al., 2018). In the East Midlands (where Leicester is located) and in Eastern regions of England, there was a higher increase in HIV exposure through sex between men $(7.3 \%$ increase in 2015 compared to 2014) than through heterosexual contact (4.82\% increase in 2015 compared to 2014) (PHE, 2018b).

In this article, we focus on the City of Leicester partly because its HIV prevalence is the highest of all local authorities in the East Midlands - approximately 4 out of 1000 residents aged 15-59 are living with HIV (PHE, 2018b). Although a significant fall in new HIV diagnoses was observed in the UK at the end of 2016 (Brown et al., 2017), the fall was less dramatic in small- and medium-sized cities in the UK, partly because of decreased awareness of, and access to, pre-exposure prophylaxis (PrEP) for HIV prevention (Nash et al., 2018).

According to PHE, the prevalence and incidence of bacterial STIs is highest in gay men, and, unlike HIV, STI incidence has consistently been on the rise. For instance, from 2013 to 2017 there was a $74 \%$ increase in chlamydia diagnoses and a $90 \%$ increase in gonorrhea diagnoses among gay men in the East Midlands. This epidemiological profile among gay men can be attributed to the high frequency of sex, multiple sexual partners, and high prevalence of condomless sex in this population (Jaspal, 2019).

\section{HIV Risk and Prevention in the Gay Sauna}

In their survey study of 134 gay sauna users in South West England, Horwood et al. (2016) found high rates of HIV risk behavior - participants reported higher numbers of casual sexual partners and higher frequency of unprotected anal sex than in community samples of gay men recruited in non-sauna settings. Moreover, gay men who engage in unprotected anal intercourse are in turn more likely to use gay saunas than those who do not (Binson, Pollack, Blair, \& Woods, 2010). Demonstrating the elevated risk of STIs in this context, Mazick et al. (2005) noted that gay sauna attendance was a significant risk factor for hepatitis A infection, and that the vast majority of those infected had had sex in a gay sauna.

Some of the sexual health initiatives in gay saunas include the dissemination of sexual health knowledge, the provision of STI screening and HIV testing, and awareness-raising regarding PrEP and post-exposure prophylaxis (PEP). In their evaluation study, Ko et al. (2009) found that a structural intervention to increase condom use for anal sex among gay men was successful in producing this effect at the 6-month followup. In recent years, there has been an increase in HIV testing in gay saunas in the US where approximately $75 \%$ of the saunas provide this service (Pollack et al., 2014). In several studies, researchers have found high acceptability and effectiveness of HIV self-testing in gay saunas although they do acknowledge the need to ascertain the best way of implementing this service within the sauna (Huebner, Binson, Pollack, \& Woods, 2012; Woods, Lippman, Agnew, Carroll, \& Binson, 2016). Crucially, HIV prevention in gay saunas can target subgroups of gay men who might not ordinarily engage with sexual health services and who might therefore be missed through conventional HIV prevention routes (Debattista, 2015).

Yet, effective interventions should be informed by social psychological research that captures the views, perceptions, and behaviors of the target population in the target context, that is, the diverse identities of the people whom we wish to target (Fish, Papaloukas, Jaspal, \& Williamson, 2016). This demonstrates the need for a social psychological approach to sexual health promotion, focusing on identity.

\section{Identity and the Gay Sauna}

Identity is a key social psychological construct that is relevant to understanding cognition and behavior (Jaspal, 2018a). Identity process theory (Breakwell, 1986) from social psychology regards identity as the unique constellation of elements that make an individual unique and distinctive. The theory identifies a series of "principles" that are essential for a positive identity - these include self-esteem, distinctiveness, self-efficacy, and distinctiveness. These principles are essentially motives for thinking and behaving in particular ways. When these principles are challenged, the individual experiences threats to identity, which is aversive for psychological wellbeing.

There has been some research that sheds light on the impact of the gay sauna on the identities of users. Bérubé (1996) described the sauna as a context in which gay men might overcome isolation and develop pride and a sense of community based on their gay identity. Thus, in addition to enhancing self-esteem, the gay sauna can potentially promote belongingness among sauna users. Belongingness refers to the "pervasive drive to form and maintain at least a minimum quantity of lasting, positive, and significant interpersonal relationships" which are characterized by "affectively pleasant interactions" and by "affective concern for each other's welfare" (Baumeister \& Leary, 1995, p. 497).

Drawing on semi-structured interviews and archival data, Prior (2009) has argued that the gay sauna played an important role in the construction of a gay culture and identity in Sydney, Australia, partly because it enabled gay men to explore, develop, and express their sexual identities in the face of the homophobic stigma they faced. The gay sauna could promote continuity and self-esteem on the basis of one's sexual identity 
in the face of external threats to this identity in the form of social stigma.

In their interview study of gay sauna users in Sydney, Australia, Prior and Cusack (2010, p. 93-94) found that the gay sauna functioned as a "religio-spiritual space removed from the influence of a dominant religious institution," which enabled its users to engage in pleasurable, self-authenticating acts away from the stigma of heteronormative Australian society. The gay sauna essentially enabled gay men to experience "the sacred" in a secular manner and to transform themselves in ways consistent with their real self. This hints at the notion that the gay sauna may promote feelings of authenticity in identity, that is, "the sense that one's life, both public and private, reflects one's real self" (George, 1998, p. 134).

In their study of 23 users of a gay sauna in Toronto, Haubrich, Myers, Calzavara, Ryder, and Medved (2004) found that users emphasized the ease of access to sex in the sauna (in contrast to gay bars, for instance), that they valued the anonymity of sexual encounters and, importantly, that they felt safe there. They also found that individuals were able to manage potential feelings of internalized homophobia through their engagement with other men in the sauna. This suggests that self-esteem can be maintained through engagement with the sauna in the face of possible threats to this principle.

Existing research suggests that the gay sauna can facilitate feelings of belonging and authenticity, in addition to the identity principles outlined in identity process theory. Jaspal, (2018a) has used identity process theory to understand, predict, and prevent HIV risk behavior in gay men. It is possible that, by understanding the role of the sauna in gay men's sense of identity, we will enhance HIV prevention efforts. Accordingly, the present study draws on tenets of identity process theory to explore the meanings and experiences that gay men living in Leicester attribute to the gay sauna, the role of the sauna in their sense of identity, and how they construe their sexual behavior in this context.

\section{Method}

\section{Participant Selection \& Data Generation}

Twenty male sauna users participated in an interview study of the sexual identity, health, and attitudes of gay sauna users. Participants were aged between 32 and 70 . The second author, who conducted the interviews, recruited the participants by approaching sauna users who entered the social area within the gay sauna. Of the 20 sauna users who participated, 16 selfidentified as gay men, 2 as bisexual, and 2 as straight-curious. Sixteen participants self-identified as White British and 4 as South Asian. All of them were born, and currently resident, in Leicester. They all believed themselves to be HIV-negative at the time of the interview.
The interviews were guided by a semi-structured interview schedule that focused on the following areas: self-description, self-categorization, motivations for using the gay sauna, sexual behaviors and experiences in the gay sauna, sexual identity, and sexual health perceptions. The interview scheduled was constructed following a review of previous research into sexual identity, wellbeing, and health among gay men (Jaspal, 2018b). Interviews lasted between 60 and $90 \mathrm{~min}$, and were digitally recorded and transcribed verbatim. Interviews were conducted by the second author in the private rooms of gay saunas. All participants were offered, and accepted, a $£ 20$ gift voucher.

\section{Analytic Approach \& Procedure}

The interview data were analyzed using thematic analysis - "a method which works both to reflect reality and to unpick or unravel the surface of "reality" and "for identifying, analyzing, and reporting patterns (themes) within data" (Braun \& Clarke, 2006, p. 79). Thematic analysis facilitates in-depth exploration of how each individual experiences the gay sauna, the meanings they attribute to it, and how they construe their sexual behavior in that context. Thematic analysis has been used to study the experiences of gay men and their sexual identity, health and wellbeing in a variety of empirical contexts (e.g., Aguinaldo, 2012; Jaspal, 2018b). The nine stages of analysis outlined by Jaspal, (2020) were followed in order to execute the thematic analysis. Initial analytic codes included inter alia participants' meaning-making, particular forms of language, and apparent contradictions and patterns within the data. These initial codes were transformed into potential themes with subsequent higher-level interpretative work. Finally, four superordinate master themes, which reflected the analysis, were developed and ordered into a coherent narrative structure. Participants' names have been replaced with pseudonyms.

\section{Results}

In this section, first, the socio-spatial characteristics of the saunas are described in order to contextualize the results of our thematic analysis of participants' interviews, and, second, we discuss the four master themes that arose from the thematic analysis. These include (1) identity authenticity in the gay sauna; (2) social connectedness among sauna users; (3) sexual risk and sexual health in the sauna; and (4) protecting the identity functions of the gay sauna.

\section{The Socio-Spatial Characteristics of the Saunas}

Each gay sauna has its own socio-spatial structure, characteristics, and cultural "norms" which in turn influence and guide 
the behavior of its users, staff members, and sexual health service providers, such as National Health Service (NHS) nurses, community workers, within these premises. For instance, a sauna may be known among its clients for attracting a particular subgroup of gay men, such as younger gay men or those with particular sexual interests, and there may be different norms in relation to condom use among clients.

Sauna A is the largest and newest of the three saunas and has a social space on the ground floor and a space for sexual activity on the first floor. It tends to attract gay men. An NHS sexual health nurse and NHS health advisor offer STI screening and sexual health counselling twice per week. Sexual health outreach is offered by a local sexual health charity.

Sauna B is the smallest of the three saunas and is also known for being frequented by non-gay identified MSM, trans women, and cross-dressers. The ground floor is for fetish activity and the first floor includes spaces for both sexual activity and socializing. An NHS sexual health nurse and NHS health advisor offer STI screening and sexual health counselling twice per week. A local sexual health charity was previously permitted to provide sexual health outreach in the sauna but is no longer permitted to do so, principally due to concerns about the impact on business.

Sauna C, which is frequented by MSM of all identities, is a medium-sized sauna with just one floor that includes spaces for both sexual activity and socializing. HIV testing is offered on a weekly basis by a local sexual health charity.

\section{Identity Authenticity in the Gay Sauna}

Several participants discussed the need to conceal aspects of their sexual identity, such as their sexual orientation or sexual preferences, in social settings outside of the sauna environment. Conversely, in the sauna, they felt empowered to explore, and to manifest more authentically, their sexual identities. As demonstrated in Olly's account, they felt more able to engage in those sexual acts that provided satisfaction:

I do not know, it's weird, it's different when you are here, just let yourself go, you are a different person because no one's judging you or you are here for the same thing, you are here for sex. (Olly, gay)

Like Olly, participants described their experience in the sauna metaphorically in terms of the ability to "let yourself go" and to become "a different person," potentially enhancing their sense of distinctiveness. The sauna was construed as a space for authentic self-presentation. Individuals were able to realize their ideal self rather than merely behave in ways that were deemed socially acceptable. This suggested a positive transition from the need for identity concealment in public settings, often characterized by heteronormativity, to the ability to explore and manifest identity authentically in the gay sauna. Moreover, there was a sense of shared, superordinate social identity in the gay sauna built around a common goal: "you're here for the same thing," that is, in pursuit of a sexual encounter with another man. This could facilitate feelings of belongingness.

Sauna users contrasted their experience in the gay sauna with the "outer world" that was perceived as heteronormative and judgmental toward norms and practices associated with homosexuality:

Then you go in here, and everyone is really friendly, which makes it even easier. Nobody is giving you looks like "what are you doing here?" or whatever. You feel at ease so you can just roam around and do whatever you want. (Karim, straight-curious)

Karim, who identified as "straight-curious," reported a sense of rejection and exclusion from some social spaces outside of the sauna setting due to his sexual identity - not least the gay scene where he derived no sense of belongingness. Moreover, interviewees pointed to a general sense of homophobia in society, which compelled them to conceal their identity. This in turn undermined their sense of identity authenticity. On the contrary, in the gay sauna, participants like Karim perceived greater accommodation of non-gay sexual identities to the extent that he and others "feel at ease." Karim's account reiterates the widespread perception among interviewees that the mainstream gay scene was not conducive to a sense of identity authenticity, but that the gay sauna was.

The perception of the gay sauna as a sexual space was elaborated to capture its inclusivity and open-mindedness. In short, participants described the sense of freedom that the sauna provided regardless of sexual identity:

I started coming to the sauna because I personally am bisexual. I'm married with a wife who understands, she knows and I like to dress up as a girl. I can come here, do all of this, it takes all of the pressure out of our relationship and it's in a safe environment. So rather than sort of, living pressure, a lie, I'm now allowed to live that and it takes all of that stress. (Jack, bisexual)

Jack, who identified as bisexual, perceived the sauna as a "safe environment" in which he could express his bisexual identity, cross-dress, and relieve the pressure associated with his heterosexual relationship. There is evidence that all of these identity elements may be subject to significant stigma in both the gay and heterosexual contexts (Sasson, 2014). Thus, the gay sauna may constitute a much-needed "escape" for individuals with these stigmatized identity elements. Jack contrasted his ability to derive a sense of authenticity in the sauna with the risk of "living a lie" outside of this environment.

Moreover, the sauna was perceived as a means of relieving himself of the psychological stress associated with the need to conform to societal pressures in relation to gender and 
sexuality. It was not possible to express his authentic identity in the outer world, while the sauna conversely was a space in which he could be "quite open about it." His account reiterated the widespread construal of the gay sauna as an inclusive sexual space in which identity authenticity was rendered possible, but also in which his continuity (between private and public identities) and belongingness could be enhanced.

\section{Social Connectedness Among Sauna Users}

As Olly indicated in his account, authenticity was also related to the sense of connection and commonality among sauna users. Although Olly noted that sauna users shared a common goal of finding sexual partners, for some interviewees, the sauna constituted not only a sexual space but also one for engaging in social interaction and for developing interpersonal relationships, thereby enhancing their sense of belongingness. These relationships were not always sexual - some were friendships. This need for social connectedness (even in the form of a "basic chat", as noted by one interviewee) was expressed particularly, but not exclusively, by older interviewees:

Well, I generally come here after work at about 5 o'clock or something like that. Generally speaking, I am just here to relax to be honest. I chat with the guys down here so I've been coming here since the beginning of the summer and I come quite frequently after work... and just chat with the guys as well. (Chris, gay)

Many people come here not only for the obvious but treat this place as a social spot as well. (Bill, gay)

Interviewees described their motivation for frequenting, and behavior within, the gay sauna. Chris, for example, reported visiting the sauna in order to "relax" after work. A key objective was to engage in casual conversation with other sauna users, rather than solely to engage in sexual behavior. Interviewees contrasted this with the experience of having to live up to heteronormative expectations within the occupational environment or at home, for instance. In the gay sauna, they could connect with like-minded others and be authentic. Thus, the gay sauna was associated with relaxation and casual socializing, rather than just with sex. Furthermore, interviewees described the benefits of frequenting the sauna for their psychological wellbeing:

I tend to come here if I'm, I've had problems with depression in the past so there's definitely your mental state and naturally you want one thing that makes me happy and whatever. (John, gay)

For John, visiting the sauna constituted a means of coping with depression. Frequenting a gay sauna has often been represented as a maladaptive coping behavior due principally to the association with high-risk sex (e.g., Jaspal et al., 2019). However, some interviewees described the positive benefits for psychological wellbeing - in fact, John referred to the sauna as the "one thing that makes me happy." It was related to his happiness. The data show that social connectedness was a key goal for most participants.

Yet, in view of the psychosocial stressors faced by some gay men, such as sexual identity issues and low levels of sexual identity disclosure, other social environments, such as bars and nightclubs, may be perceived as less conducive to social connectedness and to the formation of friendships. Furthermore, some interviewees perceived other venues, such as bars, as being inconsistent with their own identity. For instance, some were uncomfortable with the fact that alcohol was served in gay bars and nightclubs due to their religious faith, while others simply believed that the gay sauna was more conducive to conversation and interpersonal communication than gay bars. They regarded the sauna as a more accepting, inclusive, and flexible social environment:

For myself, I use this facility because I do not go drinking, I do not go clubbing, I am 37, so I have done all that in the past. (Scott, gay)

In short, the gay sauna constituted a space in which users were able to develop a sense of authenticity and to establish effective and satisfying social connections with other men, which provided respite from the feelings of loneliness and depression that some reportedly experienced. This was clearly beneficial for their sense of belongingness. The gay sauna was generally construed as a relaxing, inclusive and accepting environment, in which the "social pretense" of other gay contexts, such as gay bars and clubs, was not necessary (Haubrich et al., 2004). Perhaps, as a result of this positive construal of the gay scene, all of the interviewees reported being receptive to sexual health information in the saunas that they frequented.

\section{Sexual Risk and Sexual Health in the Sauna}

Interviewees perceived the gay sauna as a risky environment due to the availability of multiple sexual partners and the high prevalence of condomless sex. Olly noted that his fear of STIs sometimes led him to abstain from sexual contact in the sauna:

I do not know why but it scares me, STIs, I dunno. That's why sometimes I'll come on a Tuesday and will not have sex at all. I just come here and I just chill and that's fine with me but yeah it just scares me. That's why I'm always safe. (Olly, gay)

This fear sometimes led him to focus on the gay sauna as a social, rather than sexual, space. Similarly, John referred to 
condomless sex in the gay sauna as "dicing with death," highlighting his perception of HIV as a deadly virus:

Saunas, particularly in the London area or abroad, do not use many condoms to tell you the truth. If you wanna dice with death, that's up to you. I would not do that. (John, gay)

Like John, several participants perceived condoms as the only acceptable and responsible method of protecting themselves from STIs and HIV. In all three saunas, condoms and lubricants were made available to sauna users in both the social and sexual spaces of the sauna, which reinforced this perception:

I feel at ease because obviously, I see all of the condoms and the warning and everything so I'm sure everyone does take that seriously. Everyone has always been safe, so I'm guessing everyone has that same mentality about being safe and that so it just puts you at ease as well. (Karim, bi-curious)

In contrast to John and Olly, Karim perceived the gay sauna as a space for safer sex due to the availability of condoms in that environment. Indeed, some participants reported engaging in condomless sex outside of the sauna context because they did not always have access to condoms when a sexual opportunity arose. The perception of the sauna as a safe space could be attributed to the visibility of condoms and the safer sex "warnings" pervasive across the sauna. Like several other participants, Karim derived a feeling of ease from the visible culture of safer sex in the gay sauna.

Most interviewees acknowledged that there was sexual risk-taking in the context and they too had had "slip ups" in relation to condom use. However, there was a tendency for them to differentiate themselves from other sauna users who reportedly engaged in greater risk-taking. Michael described a "high-risk" man whom he encountered in the sauna:

I heard about a guy that climbed into a car with somebody or multiple guys in a lay-by somewhere and just had unprotected sex, so how can you really help people like that? (Michael, gay)

Michael contrasted the responsible self to the irresponsible other. The stigmatized practices of condomless sex and sex with multiple sexual partners were associated with other gay men not the self. There was an "otherizing" of risk (Joffe, 1999). This served to enhance identity distinctiveness, on the one hand, and to protect self-esteem from the stigma of risk, on the other hand. Moreover, sexual risk was pathologized as a trait of others, rather than as a mutable behavior. After all, Michael suggested that some gay men could simply not be "helped."
Protecting the Identity Functions of the Gay Sauna

Despite construing the gay sauna as a "high-risk" environment, participants were keen to maintain the identity functions of the gay sauna, that is, to ensure that its status as a space for identity authenticity and belongingness be maintained. Accordingly, when reflecting on the provision of NHS sexual health services in the sauna, such as HIV testing and STI screening, most interviewees perceived sexual health awareness as an individual responsibility, which was not within the remit of the sauna:

I think for this place to promote safe sex, it is not their job, it's to help with organizations come in and go "here is the information" and then they will provide it. (Scott, gay)

I think it's adequate but it's not their job to do it. No, it's not their job to do it if you are, it's your own responsibility, not here, you know. Really if you come and have sex, safe sex its good. If you have unsafe sex that's down to you and the other bloke.... 'cause, no, it's not sauna, it's not this sauna or any other sauna's job to educate. That's patronizing. (John, gay)

Although respondents acknowledged the importance of sexual health, there was a desire for the sauna to remain a space within which sexual and social interactions should have primacy. This could be attributed to the benefits for identity authenticity and belongingness, in particular. Like Scott and John, several interviewees attributed the responsibility of sexual health to external agencies that, they believed, should be permitted to undertake their outreach work in saunas, provided that this did not undermine the principal activity of the sauna and, thus, its identity functions. Indeed, John regarded the involvement of the sauna in promoting sexual health among clients as "patronizing" because of his view of sexual health as an individual, not collective, concern.

Overall, participants felt satisfied with the quantity and quality of sexual health information and support provided in the saunas. They did not necessarily expect or want more sexual health promotion work in the sauna. Interviewees did wish to separate their sauna experience from the topic of sexual health in order to safeguard the pleasurable aspects of their sauna visit - they did not want sexual health concerns to mar their sexual and social experiences in the sauna, lest this undermine its ability to enhance identity authenticity and belongingness. Thus, they accepted the presence of NHS staff who provide sexual health services - in limited sections of the sauna, at specific times and on the understanding that they did not interfere with their sexual and social activity in the sauna. However, interviewees did appreciate the nature of 
NHS staff interactions with clients in the sauna context because they deemed it to be non-judgmental and respectful:

Well, the answer is that, from our point of view, we have played Russian roulette in the past, everybody does when you are younger, and when you find yourself in an environment like this where it's very open and it's not like some big bitch nurse comes walking in the door like "what have you been doing?" You're not judged. The guys that come down here, there's no stigma, there's no judgment. (Jack, bisexual)

If people hear a problem, they do not have to go to the GP, they can come here and everything is confidential and information does not get tracked to the GPs. Unless the member is long treated wants that to happen and its kept confidential. (Dave, gay)

Sauna users acknowledged that sexual risk-taking occurred in the gay sauna, which highlighted the need for a sexual health service within this context. Crucially, participants like Jack and Dave noted that the service offered in the gay sauna was non-judgmental and devoid of social stigma, which they contrasted with sexual health services in other contexts. Indeed, it has been observed that gay men may perceive and anticipate stigma from healthcare practitioners in sexual health clinics (Jaspal, 2018b). It is easy to see how stigma can undermine identity authenticity and belongingness - people may conceal their identity to avoid stigma and feel excluded when they do experience it. The support and guidance of sexual health staff appeared to remove barriers to accessing sexual health screening in other settings:

I would not do it at home [test for HIV using a self-test kit] because some people are afraid because some people are quite young like me and Asian and you are taking it home and you are afraid that your parents will find out. It is better to just keep it discreet. (Faisal, gay)

Like Faisal, several participants highlighted the need for sexual health services in the gay sauna. Jack perceived traditional sexual health services to be unaccommodating of his sexual identity due to judgment and stigma that he reportedly encountered in such settings. Dave perceived sexual health services in the gay sauna to be more discreet than in healthcare settings - he specifically did not want his GP to know about his sexual identity or lifestyle. For all of these individuals, the provision of sexual health services in the gay sauna, which removed all of the obstacles cited by participants, filled an important gap. The availability of limited sexual health services in the sauna was consistent with participants' construal of the sauna as an inclusive sexual and social space, that is, as a space for deriving feelings of authenticity and belongingness.

\section{Discussion}

In this study, we set out to explore the meanings and experiences that male users of gay saunas in Leicester append to the sauna, the role of the gay sauna in their sense of identity and their construal of their sexual behavior in this context. The analysis yielded four themes, focusing on how the men experienced identity authenticity in the gay sauna, the opportunities for forming social connections with other sauna users, their perception of sexual risk in the sauna, and their desire to protect the identity functions of the gay sauna.

\section{Enhancing Identity in the Sauna}

There was a clear distinction drawn between the psychological "worlds" of the gay sauna and external world, respectively (Woods, Sheon, Morris, \& Binson, 2013). Outside of the sauna context, interviewees reported various forms of stigma in relation to their sexual identity and behavior, which led to shame, identity concealment, and decreased authenticity in the heteronormative environments in which they resided. Although homophobia appears to be waning in British society, in smaller cities like Leicester there may be less acceptance of sexual diversity - for instance, in 2014, there was 120 homophobic attacks in the county of Leicestershire (compared to 63 in the neighboring county of Nottinghamshire). ${ }^{2}$ Conversely, in the gay sauna, interviewees reported a sense of liberation in that they felt empowered to "be themselves," to explore their sexualities and to experience a sense of identity authenticity. Crucially, they believed that the gay sauna constituted a context in which they could realize their "true selves" in relation to their sexuality (Vannini \& Franzese, 2008). Yet, it must be noted that the gay sauna user identity may be difficult to manifest outside of the sauna environment and may, thus, remain separate from one's public identity, in view of "slut shaming" which stigmatizes sexual promiscuity among gay men (Spieldenner, 2016).

Although a sense of authenticity is generally found to be associated with self-esteem and self-efficacy (Franzese, 2007; Gecas, 1986), which are important identity principles according to identity process theory (Breakwell, 1986), there are certainly contexts in which authenticity may actually undermine these principles. For instance, sexual identity authenticity in a context in which homosexuality is stigmatized may not be conducive to self-esteem or self-efficacy due to exposure to social stigma (Crocker \& Major, 1989). Crucially, in the sauna environment, interviewees felt that they could be true to themselves given the accepting and accommodating environment that they generally encountered. It is easy to see why the gay

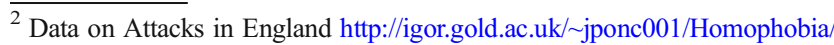
index.php/data/ Accessed 16 November 2019.
} 
sauna would be evaluated so positively by interviewees who derived feelings of authenticity in this environment.

On the one hand, individuals felt able to construct an identity that adequately reflected their sexual orientation and sexual preferences, and, on the other hand, they construed their sauna attendance as a form of "escapism" from heteronormative society. For some, frequenting the sauna helped reduce feelings of isolation, anxiety, and loneliness that are known to be prevalent among gay men (Jaspal, 2018a, 2019). The gay sauna came to represent a distinct psychological "world" for interviewees, particularly in contrast to the homophobia that they experienced outside of the sauna environment. It is noteworthy that, as a relatively small city, Leicester has a small gay community that is less visible than the gay communities in larger cities such as London and Manchester. This can contribute to greater stigma surrounding sexual minority identities and an increased risk of identity concealment and inauthenticity among gay men who anticipate stigma due to their sexual orientation or behavior.

Previous research has shown that social connectedness (or a sense of belongingness) can be an effective way of enhancing mental health and even for alleviating depressive symptomatology (Miller, Wakefield, \& Sani, 2017), which some of the men attributed to loneliness and a fragmented and exclusionary gay scene. There is a perception and lived experience among many gay men that the gay scene is exclusive, rather than inclusive, which can render this space inaccessible to some, e.g., older gay men and ethnic minority gay men (O'Byrne et al., 2014). Some participants perceived an element of stigma in relation to their non-normative sexual identities (i.e., bisexual and other non-gay identities) - men who identify with such categories may pejoratively be referred to as being in denial or as lacking authenticity. In addition, interviewees also feared general stigma toward more "mainstream" gay identities because of pervasive heteronormativity in society (Herz \& Johansson, 2015).

Hence, frequenting the sauna in order to derive a sense of belongingness could be regarded as a coping strategy and as a means of reducing the negative psychological effects of loneliness and isolation. In the gay sauna, individuals were able to communicate with other men without the "social pretense" of gay bars and nightclubs (see Haubrich et al., 2004). Furthermore, for several interviewees, the sauna constituted not only a space for seeking sexual encounters but also for deriving social support and a sense of social connectedness with other same-sex attracted men. They valued the face-to-face interaction and intimacy that geospatial gay social networking applications, for instance, could not offer (see Jaspal, 2017).

\section{Enhancing Sexual Health in the Sauna}

The gay sauna was generally perceived as a safe space in which users could derive feelings of authenticity and belongingness. However, there was acknowledgment of the gay sauna as a context in which sexual risk-taking did occur, potentially exposing users to HIV and other STIs. Some interviewees described their fear of having sex in the sauna as a result of this perceived risk. Although there was widespread acceptability of sexual health services in gay saunas, interviewees did not wish for sexual health services to encroach on the social and sexual functions of the sauna. This reflected participants' desire to protect the identity functions of the gay sauna, that is, its ability to provide authenticity and belongingness.

Due partly to the stigma that surrounds condomless sex, participants generally presented themselves as sexually "responsible" and "careful" and other sauna users as sexually "irresponsible" and "careless" (see also Jaspal \& Daramilas, 2016; Williamson, Papaloukas, Jaspal, \& Lund, 2019). This stigmatizing, moralizing representation of other gay men is supported by previous research (Jaspal \& Nerlich, 2017; Spieldenner, 2016). Individuals did not wish to present themselves as "high risk" due to the associated stigma. They clearly wished to maintain a sense of distinctiveness (from other "high-risk" gay sauna users).

\section{Implications}

This study demonstrates that gay men append various meanings to the gay sauna - some view it as a space for sexual activity, while others construe it as a context for socializing with other gay men. These meanings in turn shape the impact for identity - the sauna may enhance identity authenticity and/or belongingness. Given their phenomenological importance to participants, authenticity and belongingness may be regarded as additional identity principles in identity process theory, which guide cognition and behavior (Breakwell, 1986). The role of authenticity and belongingness in determining risk behavior will require further empirical research.

In any case, the meanings appended to the gay sauna in turn provide distinct opportunities for sexual health engagement and promotion in this context. Most HIV and sexual health promotion interventions focus primarily on components of sexual health knowledge and behavior (e.g., condom use, PrEP awareness and uptake, HIV testing, etc.), with less acknowledgment of social psychological constructs, such as identity, authenticity, and social connectedness (Fish et al., 2016). This is important for increasing the acceptability of sexual health promotion in the sauna. Practitioners must ensure that their interventions do not curtail the feelings of belongingness and authenticity that are pursued by gay sauna users.

It has been noted in previous research that gay men are at risk of poor mental health and isolation, which in turn can lead to engagement in sexual-risk taking behavior - possibly as a 
maladaptive coping strategy (Jaspal, 2018a). For some gay men who experience loneliness and isolation, the gay sauna may constitute a space in which they are able to form connections, derive feelings of intimacy, and experience better psychological wellbeing. It is noteworthy that sexual health is not restricted to the absence of STIs - it also includes social and psychological aspects of wellbeing in relation to sexuality. Furthermore, those who experience adequate levels of psychological wellbeing may be at lower risk of engaging in sexual risk-taking behaviors (Jaspal, 2018a). The experience of identity authenticity, which is associated with the gay sauna, may mean that individuals are more likely to disclose aspects of their identity, health, and wellbeing to others, enabling them to derive social support and also to access healthcare.

\section{Conclusions}

The gay sauna may not constitute the negative, "highrisk" environment that it is often purported to be in accordance with stigmatizing social representations of the sauna as a vector for infectious disease and decreased psychological wellbeing. Conversely, for some, it may in fact be conducive to acceptance, identity authenticity, and belongingness among users. This study suggests that sauna users may experience better psychological health as a result of frequenting the sauna. There may be opportunities for alleviating isolation, loneliness, and depression in the sauna. Sauna users may feel more empowered to acquire awareness and understanding of sexual health and to access sexual health services that may not be as available to them in other contexts. Sexual health promotion in the gay sauna is likely to be successful provided that it does not inhibit feelings of identity authenticity and belongingness among users. The gay sauna must continue to be a space in which we intervene to enhance the identities, lives, and wellbeing of gay men.

\section{Compliance with Ethical Standards}

Ethical Approval The study received ethics approval from the Faculty Research Ethics Committee at De Montfort University, Leicester.

Open Access This article is licensed under a Creative Commons Attribution 4.0 International License, which permits use, sharing, adaptation, distribution and reproduction in any medium or format, as long as you give appropriate credit to the original author(s) and the source, provide a link to the Creative Commons licence, and indicate if changes were made. The images or other third party material in this article are included in the article's Creative Commons licence, unless indicated otherwise in a credit line to the material. If material is not included in the article's Creative Commons licence and your intended use is not permitted by statutory regulation or exceeds the permitted use, you will need to obtain permission directly from the copyright holder. To view a copy of this licence, visit http://creativecommons.org/licenses/by/4.0/.

\section{References}

Aguinaldo, J. P. (2012). Qualitative analysis in gay men's health research: Comparing thematic, critical discourse, and conversation analysis. Journal of Homosexuality, 59(6), 765-787.

Baumeister, R. F., \& Leary, M. R. (1995). The need to belong: Desire for interpersonal attachments as a fundamental human motivation. Psychological Bulletin, 117(3), 497-529

Bérubé, A. (1996). The history of gay bathhouses. Journal of Homosexuality, 44(3), 33-53.

Binson, D., Pollack, L. M., Blair, J., \& Woods, W. J. (2010). HIV transmission risk at a gay bathhouse. Journal of Sex Research, 47(6), 580-588.

Braun, V., \& Clarke, V. (2006). Using thematic analysis in psychology. Qualitative Research in Psychology, 3(2), 77-101.

Breakwell, G. M. (1986). Coping with threatened identities. London: Methuen.

Brown, A. E., Mohammed, H., Ogaz, D., Kirwan, P. D., Yung, M., Nash, S. G., et al. (2017). Fall in new HIV diagnoses among men who have sex with men (MSM) at selected London sexual health clinics since early 2015: Testing or treatment or pre-exposure prophylaxis (PrEP)? Euro Surveillance, 22(25), 30553. https://doi.org/10.2807/ 1560-7917.ES.2017.22.25.30553.

Crocker, J., \& Major, B. (1989). Social stigma and self-esteem: The selfprotective properties of stigma. Psychological Review, 96(4), 608630.

Debattista, J. (2015). Health promotion within a sex on premises venue: Notes from the field. International Journal of STD and AIDS, 26(14), 1017-1021.

Fish, J., Papaloukas, P., Jaspal, R., \& Williamson, I. (2016). Equality in sexual health promotion: A systematic review of effective interventions for black and minority ethnic men who have sex with men. BMC Public Health, 16(810), 1-18. https://doi.org/10.1186/s12889016-3418-x.

Franzese, A. (2007). To Thine own self be true? Dissertation, Department of Sociology, Duke University, Durham, NC: An Exploration of Authenticity. Unpublished Ph.D.

Gecas, V. (1986). The motivational significance of self concept for socialization theory. In E. J. Lawyer (Ed.), Advances in group processes (volume 3) (pp. 131-156). Greenwich, CT: JAI Press.

George, L. (1998). Self and identity in later life: Protecting and enhancing the self. Journal of Aging and Identity, 3, 133-152.

Haubrich, D. J., Myers, T., Calzavara, L., Ryder, K., \& Medved, W. (2004). Gay and bisexual men's experiences of bathhouse culture and sex: 'Looking for love in all the wrong places'. Culture, Health \& Sexuality, 6(1), 19-29.

Herz, M., \& Johansson, T. (2015). The normativity of the concept of heteronormativity. Journal of Homosexuality, 62(8), 1009-1020.

Horwood, J., Ingle, S. M., Burton, D., Woodman-Bailey, A., Horner, P., \& Jeal, N. (2016). Sexual health risks, service use, and views of rapid point-of-care testing among men who have sex with men attending saunas: A cross-sectional survey. International Journal of STD and AIDS, 27(4), 273-280.

Huebner, D. M., Binson, D., Pollack, L. M., \& Woods, W. J. (2012). Implementing bathhouse-based voluntary counselling and testing has no adverse effect on bathhouse patronage among men who have sex with men. International Journal of STD and AIDS, 23(3), 182184.

Jaspal, R. (2017). Gay men's construction and management of identity on Grindr. Sexuality \& Culture, 21(1), 187-204.

Jaspal, R. (2018a). Enhancing sexual health, self-identity and wellbeing among men who have sex with men: A guide for practitioners. London: Jessica Kingsley Publishers. 
Jaspal, R. (2018b). Perceptions of HIV testing venues among men who have sex with men in London and the Midlands, UK. Journal of Gay \& Lesbian Social Services, 30(4), 336-355.

Jaspal, R. (2019). The social psychology of gay men. London: Palgrave.

Jaspal, R. (2020). Content analysis, thematic analysis and discourse analysis. In G. M. Breakwell, D. B. Wright, \& J. Barnett (Eds.), Research methods in psychology (5th ed.). London: Sage.

Jaspal, R., \& Daramilas, C. (2016). Perceptions of pre-exposure prophylaxis (PrEP) among HIV-negative and HIV-positive men who have sex with men. Cogent Medicine, 3, 1256850. https://doi.org/10. 1080/2331205X.2016.1256850.

Jaspal, R., Lopes, B., Jamal, Z., Yap, C., Paccoud, I., \& Sekhon, P. (2019). HIV knowledge, sexual health and behaviour among black and minority ethnic men who have sex with men in the UK: A crosssectional study. Sexual Health, 16(1), 25-31.

Jaspal, R., \& Nerlich, B. (2017). Polarised reporting about HIV prevention: Social representations of pre-exposure prophylaxis $(\mathrm{PrEP})$ in the UK press. Health, 21(5), 478-497.

Joffe, H. (1999). Risk and 'the other'. Cambridge: Cambridge University Press.

Keogh, P. G., \& Weatherburn, P. (2000). Tales from the backroom: Anonymous sex and HIV risk in London's commercial gay sex venues. Venereology, 13(4), 150-155.

Ko, N. Y., Lee, H. C., Hung, C. C., Chang, J. L., Lee, N. Y., Chang, C. M., Lee, M. P., Chang, H. T., \& Ko, W. C. (2009). Effects of structural intervention on increasing condom availability and reducing risky sexual behaviours in gay bathhouse attendees. AIDS Care, 21(12), 1499-1507.

Mazick, A., Howitz, M., Rex, S., Jensen, I. P., Weis, N., Katzenstein, T. L., Haff, J., \& Molbak, K. (2005). Hepatitis a outbreak among MSM linked to casual sex and gay saunas in Copenhagen, Denmark. Eurosurveillance, 10(4-6), 111-114.

Miller, K., Wakefield, J. R. H., \& Sani, F. (2017). On the reciprocal effects between multiple group identifications and mental health: A longitudinal study of Scottish adolescents. Journal of Clinical Psychology, 56(4), 357-371.

Nash, S., Desai, S., Croxford, S., Guerra, L., Lowndes, C., Connor, N. \& Gill ON. (2018). Progress towards ending the HIV epidemic in the United Kingdom: 2018 report. London: Public Health England. https://assets.publishing.service.gov.uk/government/uploads/ system/uploads/attachment_data/file/759408/HIV_annual_report_ 2018.pdf accessed 20 June 2019.

O’Byrne, P., Bryan, A., Hendriks, A., Horvath, C., Bouchard, C., \& Etches, V. (2014). Social marginalization and internal exclusion:
Gay men's understandings and experiences of community. Canadian Journal of Nursing Research, 46(2), 57-79.

PHE (2018a). National HIV surveillance data tables. https://assets. publishing.service.gov.uk/government/uploads/system/uploads/ attachment data/file/768932/National Tables 2018 v1.2.xls Accessed on 20 June 2019.

PHE (2018b). Country and PHE region HIV data tables. https://assets. publishing.service.gov.uk/government/uploads/system/uploads/ attachment_data/file/738224/Country_Tables_2018.xls Accessed on 20 June 2019.

Pollack, L. M., Woods, W. J., Blair, J., \& Binson, D. (2014). Presence of an HIV testing program lowers the prevalence of unprotected insertive anal intercourse inside a gay bathhouse among HIVnegative and HIV-unknown patrons. Journal of HIV/AIDS \& Social Services, 13(3), 306-323.

Prior, J. (2009). Experiences beyond the threshold: Sydney's gay bathhouses. Australian Cultural History, 27(1), 61-77.

Prior, J., \& Cusack, C. M. (2010). Spiritual dimensions of self-transformation: In Sydney's gay bathhouses. Journal of Homosexuality, 57, 71-97.

Sasson, E. (2014). Why are Americans more accepting of gays and lesbians than bisexuals and cross-dressers? The New Republic, 28 April 2014. https://newrepublic.com/article/117526/bisexuals-andcross-dressers-lag-gays-and-lesbians-wider-acceptance Accessed 21 June 2019.

Spieldenner, A. (2016). PrEP whores and HIV prevention: The queer communication of HIV pre-exposure prophylaxis (PrEP). Journal of Homosexuality, 63, 1685-1697.

Vannini, P., \& Franzese, A. (2008). The authenticity of self: Conceptualization, personal experience, and practice. Sociology Compass, 2(5), 1621-1637.

Williamson, I., Papaloukas, P., Jaspal, R., \& Lund, B. (2019). 'Here's this glorious pill': Gay and bisexual men in the English Midlands navigate risk and responsibility in the age of pre-exposure prophylaxis. Critical Public Health, 28(5), 560-571.

Woods, W. J., Sheon, N., Morris, J. A., \& Binson, D. (2013). Gay bathhouse HIV prevention: The use of staff monitoring of patron sexual behavior. Sexuality Research \& Social Policy, 10(2), 77-86.

Woods, W. J., Lippman, S. A., Agnew, E., Carroll, S., \& Binson, D. (2016). Bathhouse distribution of HIV self-testing kits reaches diverse, high-risk population. AIDS Care, 28(Suppl 1), 111-113.

Publisher's Note Springer Nature remains neutral with regard to jurisdictional claims in published maps and institutional affiliations. 